Article

\title{
Effects of Phlomis umbrosa Root on Longitudinal Bone Growth Rate in Adolescent Female Rats
}

\author{
Donghun Lee, Young-Sik Kim, Jungbin Song, Hyun Soo Kim, Hyun Jung Lee, Hailing Guo and \\ Hocheol Kim * \\ Department of Herbal Pharmacology, College of Korean Medicine, Kyung Hee University, Seoul 130-701, Korea; \\ allstart2925@naver.com (D.L.); yjbsik@naver.com (Y.-S.K.); jbsong0527@gmail.com (J.S.); \\ lovelyradix@hanmail.net (H.S.K.); lhjung91@hanmail.net (H.J.L.); guohailing1026@gmail.com (H.G.) \\ * Correspondence: hckim@khu.ac.kr; Tel.: +82-2-961-0419; Fax: +82-2-964-0325 \\ Academic Editor: Derek J. McPhee \\ Received: 2 March 2016; Accepted: 31 March 2016; Published: 7 April 2016
}

\begin{abstract}
This study aimed to investigate the effects of Phlomis umbrosa root on bone growth and growth mediators in rats. Female adolescent rats were administered P. umbrosa extract, recombinant human growth hormone or vehicle for 10 days. Tetracycline was injected intraperitoneally to produce a glowing fluorescence band on the newly formed bone on day 8 , and 5-bromo-2'-deoxyuridine was injected to label proliferating chondrocytes on days $8-10$. To assess possible endocrine or autocrine/paracrine mechanisms, we evaluated insulin-like growth factor-1 (IGF-1), insulin-like growth factor binding protein-3 (IGFBP-3) or bone morphogenetic protein-2 (BMP-2) in response to $P$. umbrosa administration in either growth plate or serum. Oral administration of $P$. umbrosa significantly increased longitudinal bone growth rate, height of hypertrophic zone and chondrocyte proliferation of the proximal tibial growth plate. P. umbrosa also increased serum IGFBP-3 levels and upregulated the expressions of IGF-1 and BMP-2 in growth plate. In conclusion, $P$. umbrosa increases longitudinal bone growth rate by stimulating proliferation and hypertrophy of chondrocyte with the increment of circulating IGFBP-3. Regarding the immunohistochemical study, the effect of P. umbrosa may also be attributable to upregulation of local IGF-1 and BMP-2 expressions in the growth plate, which can be considered as a GH dependent autocrine/paracrine pathway.
\end{abstract}

Keywords: Phlomis umbrosa; bone growth rate; IGF-1; growth plate

\section{Introduction}

Short stature is defined as the height of an individual more than two standard deviation score (SDS) below the average height for an age, sex, and population group [1]. Short children might have a high frequency of psychosocial problems such as lower self-esteem, social immaturity, or being bullied [2-5]. People with shorter height are reported to have a lower health-related quality of life even if they do not fit into the definition of short stature [6]. People with shorter height also have higher morbidity of coronary heart diseases, perhaps because of the smaller diameter of their blood vessels $[7,8]$.

Short stature caused by certain diseases, including growth hormone (GH) deficiency, accounts for $20 \%$ of all short children, but the remaining $80 \%$ are not determined, so-called idiopathic short stature (ISS) [1]. In case of GH deficiency, average increase in final height attributable to GH therapy is about $30 \mathrm{~cm}$ compared with predicted adult height $[9,10]$. In the case of ISS, the US FDA approved GH therapy in ISS children shorter than -2.25 SDS in 2003 based on the evidence derived from two clinical studies [11,12], nevertheless, the average increase in final height attributable to GH therapy in children with ISS is just 3.5-7.5 cm (4-7 years) [11,13-16]. In this case of ISS, the effect remains controversial because the estimated cost of GH therapy for adult height gain is about 10,000-20,000 dollars/cm $[1,15]$. 
Moreover, children's pain due to daily injection and abuse of human GH to increase the height of children who are already of normal height are also considered controversial $[17,18]$.

For these reasons, alternative oral growth stimulators with relatively low cost are currently being studied. Up to now, aromatase inhibitors, arginine, which is an essential amino acid for children, and zinc, which is an essential micronutrient, have been studied to stimulate bone growth or GH secretion. Aromatase inhibitors can delay puberty, thereby increasing the growth rate of male children in clinical trials, but their safety of delayed puberty has not yet been demonstrated [19]. Arginine increases GH secretion when it is administered intravenously; nevertheless, this effect only lasts for a few hours and it is often ineffective when administered orally [20]. Supplementation of zinc increases longitudinal growth rate in the children with zinc-deficiency, but it is not effective in cases of healthy normal children [21,22].

In accordance with traditional Korean medicinal theory that height growth of children occurs under the influence of innate $q i$ and acquired $q i$, medicinal herbs which are used to tonify innate $q i$ or acquired $q i$ were selected from the Dongeuibogam. We have screened natural products to develop the safe growth stimulators with health benefits by an established in vivo model which can evaluate the bone growth rate in adolescent rats using tetracycline [23]. The root of Phlomis umbrosa Turcz. (Lamiaceae) was identified as one of the most effective herbs in this screening process.

P. umbrosa, also known as Hansokdan, Sokdan, or Caosu was used as Xu Duan, which is widely used to strengthen the muscles and bones and treat bone fractures, until the Song dynasty in China. P. umbrosa was also used as Sokdan (Xu Duan) in Korea, including Dongeuibogam, until the twentieth century $[8,24,25]$. Among the Tujia people of China, P. umbrosa root has been used to treat rheumatic disease, bone fractures and bleeding. P. umbrosa was reported to have anti-allergic, anti-inflammatory, and anti-nociceptive effects [26-28]. P. umbrosa contains iridoids and phenylethylalcohol, and the most prevalent iridoids are 8-O-acetylshanzhiside methyl ester, lamiide and shanzhiside methyl ester, known to be responsible for its diverse biological activities $[29,30]$. The compound 8-O-acetylshanzhiside methyl ester has been reported to attenuate cerebral ischemia and myocardial ischemia injury through anti-inflammatory mechanism, and improve angiogenesis and functional recovery after cerebral ischemia [31-33].

Height growth is the consequence of proliferation and hypertrophy of chondrocytes in the growth plates, which is called endochondral ossification, and this is caused by direct stimulation of GH or circulating insulin-like growth factor-1 (IGF-1) [34,35]. To increase the adult height, the growth rate should be increased without affecting growth period and the rate is determined by the rate of chondrocyte proliferation, subsequent differentiation and mineralization in certain period of time [36].

To observe the daily bone growth rate, tetracycline was used in this study as an intravital marker to stain newly formed bone in the growth plate, [37]. We have also analyzed the effects of $P$. umbrosa on zonal height and chondrocyte proliferation in growth plate of proximal tibia. To assess the possible endocrine/paracrine mechanism whereby $P$. umbrosa exerts its growth-promoting effects, we evaluated the IGF-1, insulin-like growth factor binding protein-3 (IGFBP-3) or bone morphogenetic protein-2 (BMP-2) in response to $P$. umbrosa administration in either growth plate or serum.

\section{Results}

\subsection{HPLC Analysis of P. umbrosa Extract}

P. umbrosa extract was standardized to contain $6.62 \mathrm{mg} / \mathrm{g}$ of shanzhiside methyl ester. A three dimensional HPLC chromatogram and the structures of the constituent compounds are shown in Figure 1. 


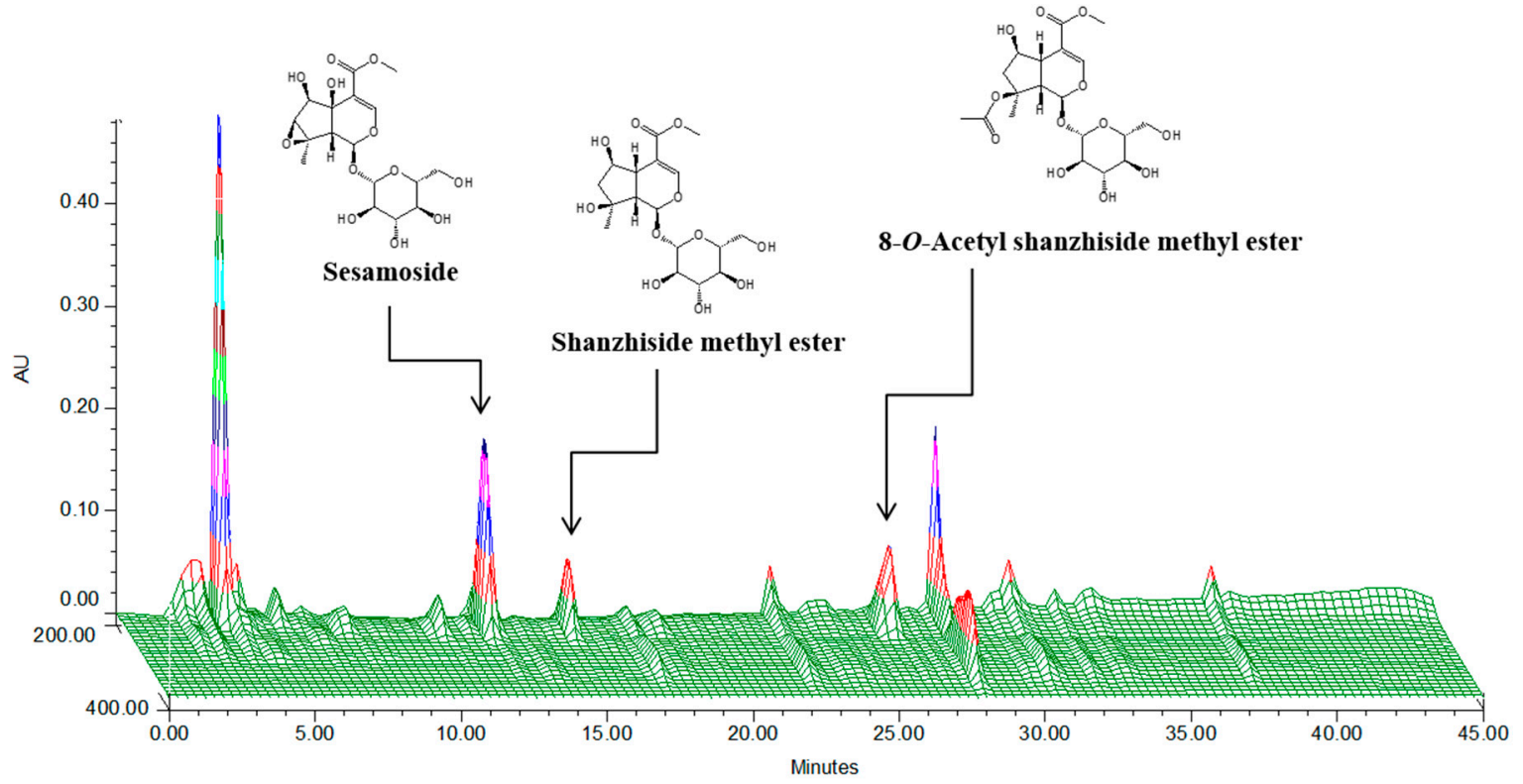

Figure 1. Three-dimensional high-performance liquid chromatogram for standardization of P. umbrosa.

\subsection{Effect on Longitudinal Bone Growth Rate}

To evaluate the effect of $P$. umbrosa on longitudinal bone growth rate, tetracycline was used as a fluorescent marker to label the newly formed bone under the growth plate of the proximal tibia. The double-headed arrow indicates the length of bone growth in the proximal tibial growth plate during a $72 \mathrm{~h}$ period (Figure 2A). The distance was significantly increased by oral administration of $P$. umbrosa at doses of 100 or $300 \mathrm{mg} / \mathrm{kg}$ compared with the control group. Figure $2 \mathrm{~B}$ shows the numerical values of longitudinal bone growth rate. Longitudinal bone growth rate in the control group was $358.2 \pm 22.0 \mu \mathrm{m} /$ day, and in rhGH treated group was $406.9 \pm 21.1 \mu \mathrm{m} /$ day. Oral administration of 100 and $300 \mathrm{mg} / \mathrm{kg}$ P. umbrosa significantly increased the longitudinal bone growth rate exhibiting $380.9 \pm 21.1$, and $381.5 \pm 22.5 \mu \mathrm{m} /$ day compared with the control group, respectively.
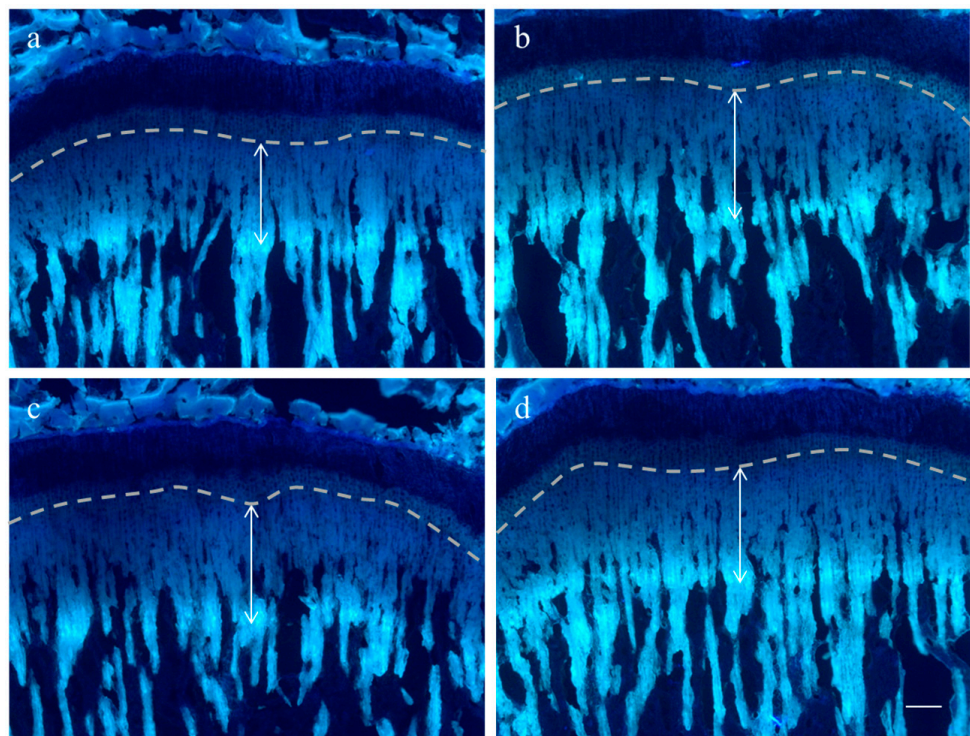

(A)

Figure 2. Cont. 


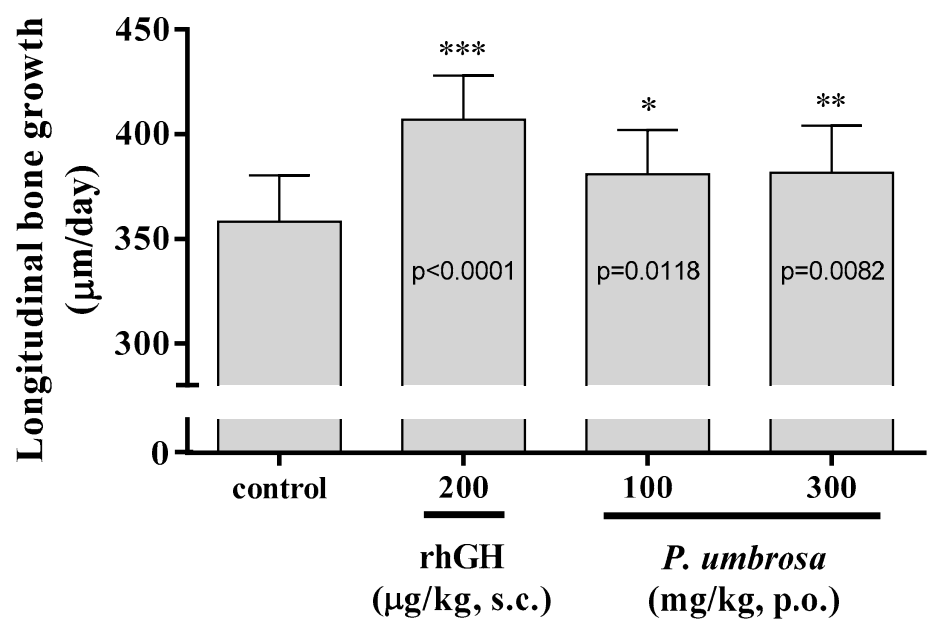

(B)

Figure 2. (A) Representative fluorescence photomicrographs of sagittal sections of the proximal tibial growth plate in rats. The double-headed arrow shows the distance between the chondro-osseous junction within the growth plate and the proximal endpoint of the tetracycline label which indicates the length of bone growth in proximal tibial growth plate during $72 \mathrm{~h}$ period. (a) vehicle treated control group; (b) rhGH $200 \mu \mathrm{g} / \mathrm{kg}$ (s.c.) treated group; (c) P. umbrosa $100 \mathrm{mg} / \mathrm{kg}$ (p.o.) treated group; (d) P. umbrosa $300 \mathrm{mg} / \mathrm{kg}$ (p.o.) treated group. The scale bar is $200 \mu \mathrm{m}$; (B) Effects of P. umbrosa on longitudinal bone growth rate in proximal tibial growth plate. Each value is the mean \pm SD. The number of animals is $14-21$ per group; ${ }^{*} p<0.05,{ }^{* *} p<0.01$ and ${ }^{* * *} p<0.001$ vs. control (one-way ANOVA, Bonferroni test).

\subsection{Effect on Growth Plate Height}

Proximal tibial growth plate height was measured using CV staining. Typical images of sections stained with CV are shown in Figure 3. The overall height of growth plate was $453.8 \pm 28.6 \mu \mathrm{m}$ in the control group and in the rhGH treated group it was $536.9 \pm 29.5 \mu \mathrm{m}$. Oral administration of $300 \mathrm{mg} / \mathrm{kg}$ P. umbrosa significantly increased growth plate height, reaching $508.6 \pm 28.9 \mu \mathrm{m}$ compared with the control group. The heights of the hypertrophic zones, especially, were significantly increased in the rhGH and P. umbrosa groups (Table 1) compared to the control groups.

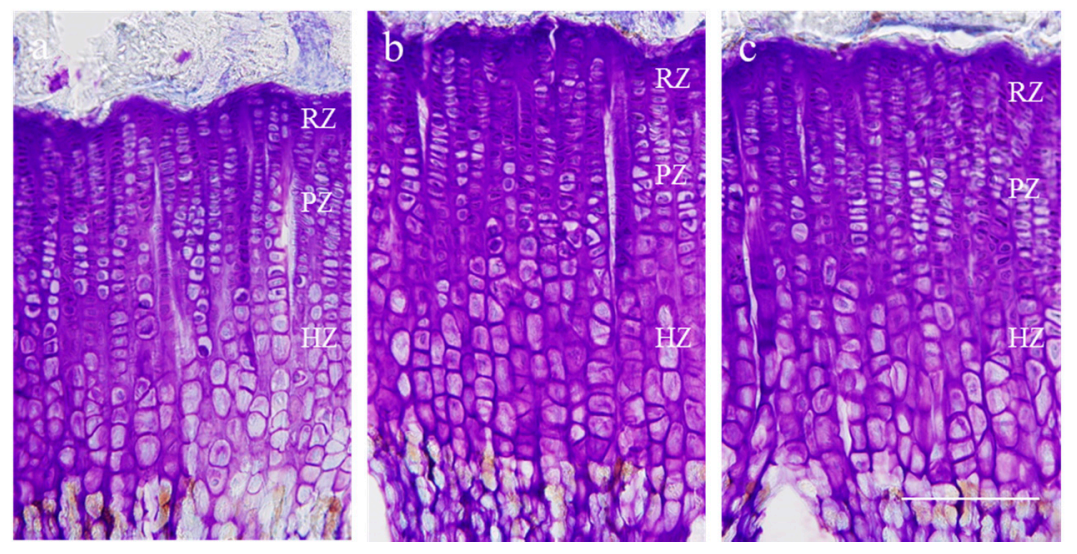

Figure 3. Representative photomicrographs of cresyl violet-stained chondrocytes of the proximal tibial growth plate in rats. (a) vehicle treated control group; (b) rhGH $200 \mu \mathrm{g} / \mathrm{kg}$ (s.c.) treated group; (c) P. umbrosa $300 \mathrm{mg} / \mathrm{kg}$ (p.o.) treated group, RZ: resting zone, PZ: proliferative zone, HZ: hypertrophic zone. The scale bar is $200 \mu \mathrm{m}$. 
Table 1. Zonal height of each group in growth plate of proximal tibia in rats.

\begin{tabular}{cccc}
\hline Height $(\mu \mathrm{m})$ & Control & rhGH $200 \mu \mathbf{g} / \mathbf{k g}$ (s.c.) & P. umbrosa $\mathbf{3 0 0 ~} \mathbf{~ m g} / \mathbf{k g}$ (p.o.) \\
\hline Overall growth plate & $453.8 \pm 28.6$ & $536.9 \pm 29.5^{* * *}$ & $508.6 \pm 28.9^{* *}$ \\
Resting zone & $27.3 \pm 3.5$ & $25.1 \pm 2.9$ & $29.8 \pm 2.5$ \\
Proliferative zone & $111.7 \pm 23.1$ & $110.0 \pm 30.0$ & $120.9 \pm 5.9$ \\
Hypertrophic zone & $304.0 \pm 46.1$ & $384.0 \pm 54.2^{* *}$ & $345.0 \pm 22.0^{*}$ \\
\hline
\end{tabular}

Data are shown as mean $\pm \mathrm{SD}$. The number of animals is eight per group; ${ }^{*} p<0.05,{ }^{* *} p<0.01$ and ${ }^{* * *} p<0.001$ vs. control.

\subsection{Effect on Chondrocyte Proliferation}

BrdU-labeled cells were observed to assess chondrocytes proliferation in the proximal tibial growth plate (Figure 4A). The number of BrdU-labeled chondrocytes of the growth plate in the control group was $17.8 \pm 3.3$ cells $/ \mathrm{mm}^{2}$ and in the rhGH group was $24.4 \pm 4.4$ cells $/ \mathrm{mm}^{2}$. BrdU-labeled chondrocytes in the $P$. umbrosa at doses of 100 and $300 \mathrm{mg} / \mathrm{kg}$ group also significantly increased, to $20.3 \pm 2.2$ cells $/ \mathrm{mm}^{2}$ and $22.0 \pm 6.2$ cells $/ \mathrm{mm}^{2}$, respectively (Figure $4 \mathrm{~B}$ ).
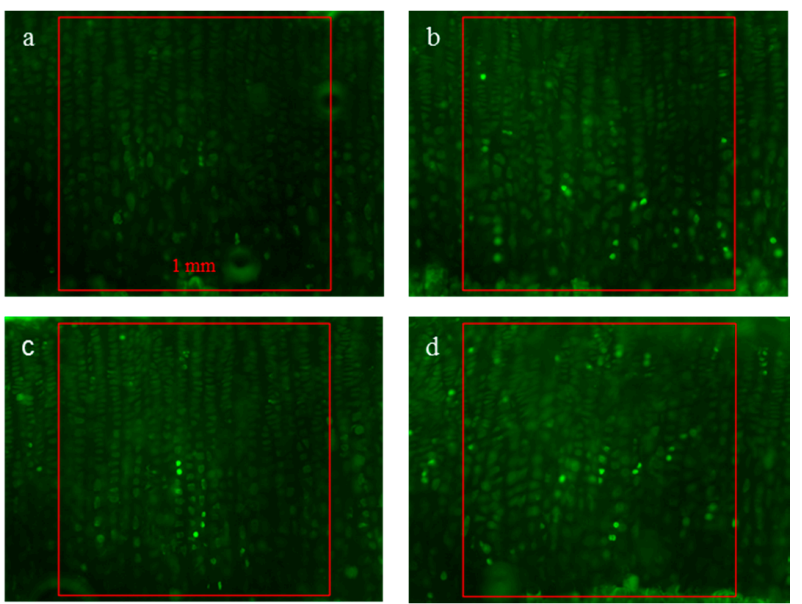

(A)

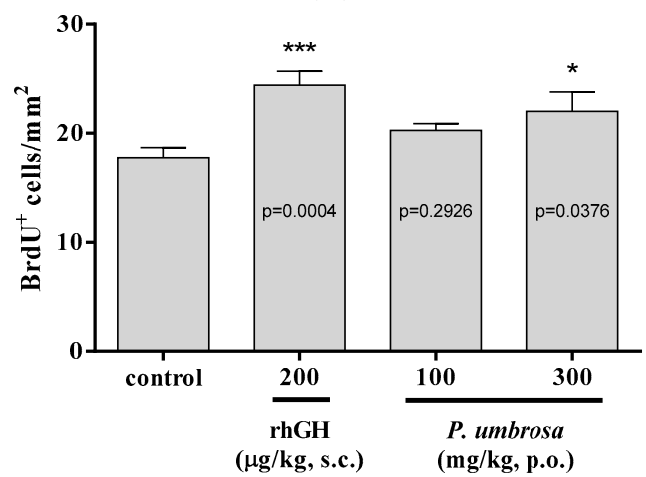

(B)

Figure 4. (A) Representative photomicrographs of 5-bromo-2'-deoxyuridine (BrdU)-labeled chondrocytes of the proximal tibial growth plate, Green: BrdU-labeled chondrocyte, (a) vehicle treated control group; (b) rhGH $200 \mu \mathrm{g} / \mathrm{kg}$ (s.c.) treated group; (c) P. umbrosa $100 \mathrm{mg} / \mathrm{kg}$ (p.o.) treated group; (d) . umbrosa $300 \mathrm{mg} / \mathrm{kg}$ (p.o.) treated group. Each box area is $1 \mathrm{~mm}^{2}$; (B) Effects of $P$. umbrosa on chondrocyte proliferation of proximal tibial growth plate in female adolescent rats. Each value is the mean $\pm \mathrm{SD}$. The number of animals is four per group; ${ }^{*} p<0.05$ and ${ }^{* * *} p<0.001$ vs. control (one-way ANOVA, Bonferroni test). 


\subsection{Effects on IGF-1 and BMP-2 Expression}

Protein expression of IGF-1 and BMP-2 in the proximal tibial growth plate was assessed with antigen-specific immunohistochemistry. IGF-1 was more highly expressed in hypertrophic zones than in resting and proliferative zones. Administration of $P$. umbrosa or rhGH remarkably increased the intensity of IGF-1 expression in proliferative and hypertrophic zone compared with control. BMP-2 expression was also higher in hypertrophic zones and markedly increased by administration of P. umbrosa or rhGH particularly (Figure 5).
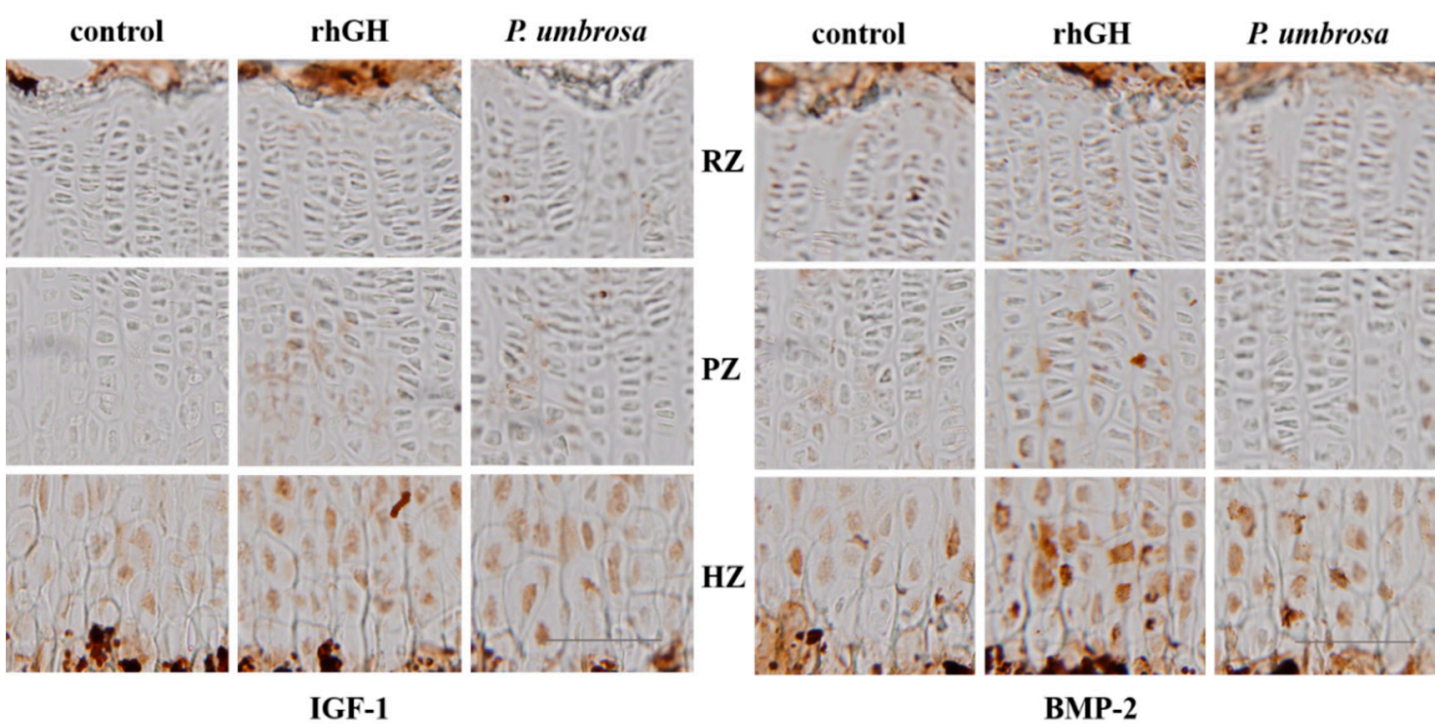

Figure 5. Immunohistochemical localization of insulin-like growth factor-1 and bone morphogenetic protein-2 on the proximal tibial growth plate in rats, control: vehicle treated control group, rhGH: rhGH $200 \mu \mathrm{g} / \mathrm{kg}$ (s.c.) treated group, P. umbrosa: P. umbrosa $300 \mathrm{mg} / \mathrm{kg}$ (p.o.) treated group, RZ: resting zone, PZ: proliferative zone, HZ: hypertrophic zone. The scale bar is $100 \mu \mathrm{m}$.

\subsection{Effect on Serum IGF-1 and IGFBP-3 Concentrations}

To evaluate the effect of P. umbrosa on serum IGF-1 and IGFBP-3 concentrations, serum concentrations were measured by specific ELISA at $12 \mathrm{~h}$ after treatment, which is reported as the highest point of serum IGF-1 and IGFBP-3 concentration after single injection of rhGH in rats [38]. P. umbrosa at doses of 100,300 and $1000 \mathrm{mg} / \mathrm{kg}$ showed a dose-dependent increment of serum IGFBP-3 level that reached $48.4 \%$ at $1000 \mathrm{mg} / \mathrm{kg}$ compared to the control group. Serum IGF-1 level was slightly higher at every dose level but not significantly different compared to the control group (Figure 6).

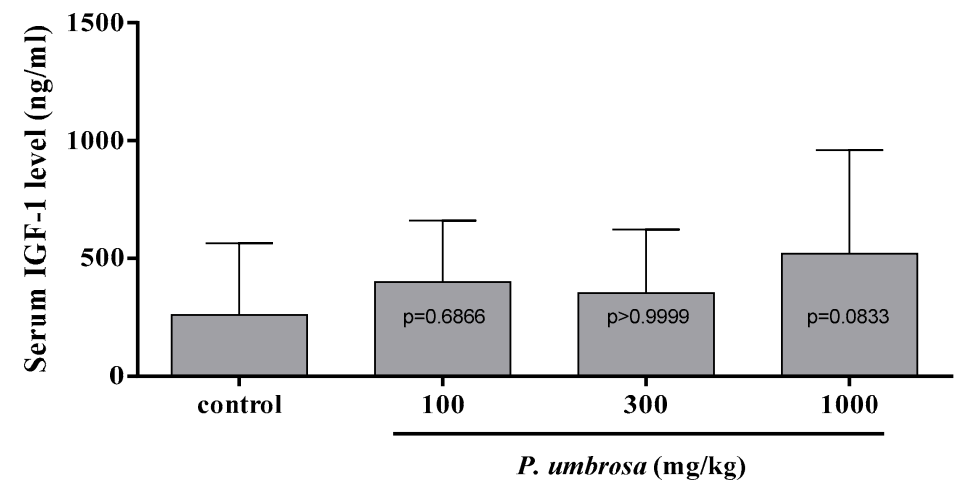

(A)

Figure 6. Cont. 


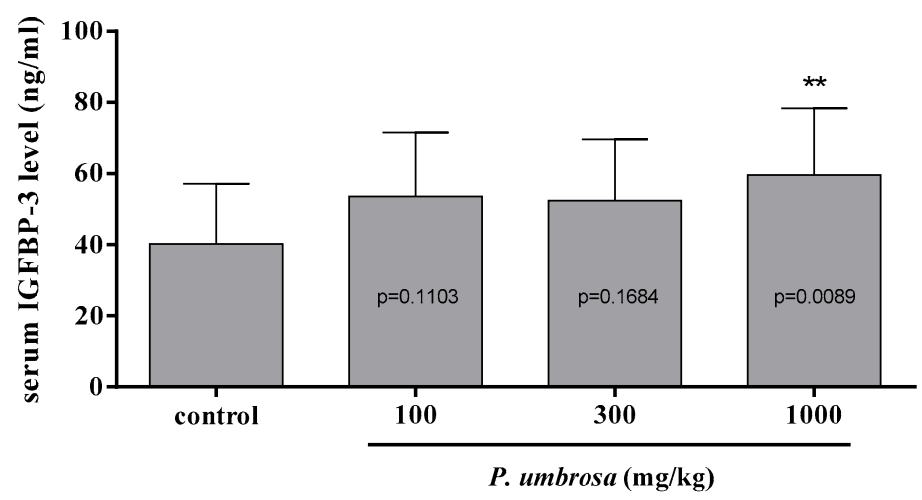

(B)

Figure 6. (A) Serum insulin-like growth factor-1 concentration for each group at $12 \mathrm{~h}$ after treatment; (B) Serum insulin-like growth factor binding protein-3 concentration for each group at $12 \mathrm{~h}$ after treatment. Each value is the mean $\pm \mathrm{SD}$. The number of animals is sixteen per group; ${ }^{* *} p<0.01 \mathrm{vs}$. control (one-way ANOVA, Bonferroni test).

\section{Discussion}

Oral administration of $70 \% \mathrm{EtOH}$ extracts of P. umbrosa significantly increased longitudinal bone growth rate, height of hypertrophic zone, and chondrocyte proliferation of the proximal tibial growth plate compared to control. P. umbrosa also increased serum IGFBP-3 levels and upregulated the expressions of IGF-1 and BMP-2 in hypertrophic zone of the growth plate.

P. umbrosa called Xu Duan, which literally means "reconnect what is broken", was used to treat bone fractures in traditional medicine. Bone fracture recovery involves a process of endochondral ossification by proliferation and differentiation of chondrocytes and osteoblasts, which mimics the process of longitudinal bone growth [25]. Moreover, the dichloromethane subfraction of P. umbrosa extracts has been reported to increase new bone formation of calvarial defects in rats and increase collagen synthesis and alkaline phosphatase activity in primary cultured osteoblast derived from alveolar bone [39,40]. These mechanisms might be shared with the effects of P. umbrosa on the stimulation of longitudinal bone growth rate.

P. umbrosa at doses of 100 and $300 \mathrm{mg} / \mathrm{kg}$ was shown to increase the bone growth rate to 380.9 and $381.5 \mu \mathrm{m} /$ day in the proximal tibial growth plate, respectively. The bone growth rate in the control group was $358.2 \mu \mathrm{m} /$ day in accordance with the results reported previously [41]. Tetracycline gets deposited in newly formed bones, causing a fluorescent line corresponding to the injection, and the distance between the chondro-osseous junction and the fluorescent line indicates the growth rate, which is the length of bone growth during a certain period of time [37]. The result suggests that P. umbrosa increases longitudinal bone growth rate.

P. umbrosa at dose of $300 \mathrm{mg} / \mathrm{kg}$ significantly increased overall height of growth plate by $12.8 \%$ especially that of hypertrophic zone by $13.5 \%$ compared to the control group in the proximal tibial growth plate. Growth plate consists of chondrocytes with three distinctive histological areas: resting, proliferative and hypertrophic zones [18]. Rapid chondrocyte division in the proliferative zone and substantial chondrocyte enlargement in the hypertrophic zone lead to increase in bone growth rate and growth plate height [42]. Especially, the greatest contribution to the overall height of growth plate increment is the increase in hypertrophic zone height which reflects the rapid longitudinal bone growth rate $[24,43]$. Previous studies have found good correlations between bone growth rate and the height of hypertrophic zone, regardless of bone location or animal age [44-46]. The result suggests that $P$. umbrosa increases the height of growth plate, especially that of the hypertrophic zone.

Because the bone growth rate is equal to the product of the rate of proliferation and the size of hypertrophic chondrocyte, the proliferation of chondrocytes in the growth plate is a critical determinant of the increase in body length [42]. In the present study, proliferation of chondrocyte was determined 
experimentally by counting labeled nuclei by BrdU, a thymidine analog that incorporates into newly synthesized DNA in proliferating cells during the S-phase of cycle [47]. The number of BrdU-labeled cells in $P$. umbrosa group significantly increased compared to the control group, suggesting that P. umbrosa increases proliferation rate of chondrocytes in the growth plate.

P. umbrosa increased the expressions of local IGF-1 and BMP-2 in the proliferative and hypertrophic zones of the tibial growth plate. Bone growth is the outcome of chondrocyte proliferation and hypertrophy of the growth plates caused by either circulating IGF-1 secreted from the liver by GH or local IGF-1 production by direct stimulation of GH. Local IGF-1 production is mainly dependent on serum GH and is combined with IGF-1 receptor expressed on the cell surface of the chondrocytes in the growth plate, like systemic IGF-1 [17]. Locally expressed IGF-1 in the growth plate is the primary mediator of the direct effects of $\mathrm{GH}$ on the longitudinal bone growth rate [48,49]. Regarding other factors affecting GH, BMP-2 expressed in the growth plate has been reported to accelerate the bone growth by stimulating proliferation and hypertrophy of chondrocytes in an organ culture model [50]. Recently, it has been reported that circulating GH increases local production of BMP-2 in the growth plate while circulating IGF-1 does not affect its local production [51]. These findings suggest that GH-dependent increase of BMP-2 production in the growth plate may be attributable to direct growth-promoting effects of $\mathrm{GH}$. Taken together, the results suggest that growth stimulating effects of P. umbrosa might be attributable to local IGF-1 and BMP-2 expression stimulated by the direct effect of GH on the local growth plate.

Oral administration of P. umbrosa at doses of $100,300 \mathrm{and} 1000 \mathrm{mg} / \mathrm{kg}$ at $12 \mathrm{~h}$ before sacrifice, showed dose-dependent increment of serum IGFBP-3 level that reached $48.4 \%$ at $1000 \mathrm{mg} / \mathrm{kg}$ compared to the control group. Serum IGF-1 level was slightly higher at every dose level but not significantly different compared to the control group. This result concurs with other studies showing that the level of IGFBP-3 may be superior to the measurement of IGF-1 in the diagnosis of GH deficiency [52,53], and in reflecting actual serum levels of IGF-1 [54]. It is well known that IGF-1 transport is mediated mainly by IGFBP-3 [55] and IGFBP-3 is considered as a biochemically excellent index of GH level because it is GH dependent and is maintained at a regular daily concentration [56]. Our results suggest that the effect of $P$. umbrosa on longitudinal bone growth rate may also be mediated by the increment in serum IGF-1 and IGFBP-3 concentrations stimulated by GH.

In summary, P. umbrosa increases the longitudinal bone growth rate accompanying promotion of chondrocyte proliferation and differentiation, with the increment of circulating IGFBP-3. Regarding the immunohistochemical study, the effect of $P$. umbrosa may also be attributable to upregulating local IGF-1 and BMP-2 expressions in the growth plate, which can be considered as normal functioning of GH dependent autocrine/paracrine pathway. Based on these findings, it is tempting to speculate that P. umbrosa may be a therapeutic candidate for the children with short stature.

\section{Experimental Section}

\subsection{Plant Material}

The root of P. umbrosa was purchased from the Zhashui Livelihood and Welfare Company (Shaanxi, China). P. umbrosa was identified by Dr Hocheol Kim, Department of Herbal Pharmacology, Kyung Hee University, where a voucher specimen (\#HP125) was deposited on 29 January 2015.

\subsection{Sample Preparation and HPLC Analysis}

The dried roots of P. umbrosa were extracted in a reflux apparatus $(70 \%$ aqueous ethanol, $6 \mathrm{~h}$ at $80^{\circ} \mathrm{C}$ ). The filtered extract was lyophilized after concentration under reduced pressure. The yield of extract was $20.3 \%$. The quantitative analysis of P. umbrosa performed by HPLC. The HPLC system consisted of a 1525 pump (Waters, Milford, MA, USA), a 2707 autosampler and a Waters 2998 PDA. Separation was achieved on Waters Sunfire ${ }^{\mathrm{TM}} \mathrm{C}^{18}(250 \mathrm{~mm} \times 4.6 \mathrm{~mm}$ i.d., $5 \mu \mathrm{m})$ column at $40{ }^{\circ} \mathrm{C}$. The mobile phase composition was $0.5 \% \mathrm{H}_{3} \mathrm{PO}_{4}(\mathrm{~A})$ and acetonitrile (B) eluted for separation as 
following: $0-20 \mathrm{~min}, 5 \%-17 \% ; 20-30 \mathrm{~min}, 17 \%-22 \%$; 30-40 $\mathrm{min}, 22 \%-30 \%$ solvent $\mathrm{B}$. The flow rate was $1.0 \mathrm{~mL} / \mathrm{min}$. The injection volume was $5 \mu \mathrm{L}$ and effluent was monitored at $235 \mathrm{~nm}$. The extract was analysed in triplicate. Shanzhiside methyl ester was chosen as a marker compound to standardize the extract because of its characteristic peak and good stability in aqueous solution.

\subsection{Animals}

Twenty-five-day-old female Sprague-Dawley rats were obtained from Samtako (Osan, Korea). This study was done in accordance with the guidelines of the Institutional Animal Care and Use Committee of Kyung Hee University (KHUASP[SE]-13-028). All animals were housed under controlled conditions $\left(22 \pm 1{ }^{\circ} \mathrm{C}, 12 \mathrm{~h}\right.$ of light starting at 07:00) in an isolated ventilated chamber with food and water available ad libitum.

\subsection{Treatment}

After 7 days of acclimatization, rats were divided into four groups: control, P. umbrosa $100 \mathrm{mg} / \mathrm{kg}$, P. umbrosa $300 \mathrm{mg} / \mathrm{kg}$ and recombinant human GH (rhGH) $200 \mu \mathrm{g} / \mathrm{kg}$. Vehicle, P. umbrosa $100 \mathrm{mg} / \mathrm{kg}$ or P. umbrosa $300 \mathrm{mg} / \mathrm{kg}$ were orally administered twice daily (8:30 a.m.; 8:30 p.m.) and rhGH $200 \mu \mathrm{g} / \mathrm{kg}$ (Eutropin, LG Life Sciences, Seoul, Korea) was subcutaneously injected once daily (8:30 a.m.) for 10 consecutive days. On the 11th day, rats were sacrificed for analysis.

\subsection{Longitudinal Bone Growth Rate}

Tetracycline hydrochloride was injected intraperitoneally $72 \mathrm{~h}$ prior to sacrifice $(20 \mathrm{mg} / \mathrm{kg}$, Sigma Aldrich, St. Louis, MO, USA). Tibias were dissected, fixed with 4\% paraformaldehyde, decalcified in $50 \mathrm{mM}$ ethylenediaminetetraacetic acid solution (Sigma Aldrich). After dehydration in $30 \%$ sucrose, the samples were cut at sagittal sections of the proximal part with thickness of $40 \mu \mathrm{m}$ using a cryostat (CM3050S, Leica Microsystems, Berlin, Germany). Bone growth rate per day was assessed by measuring distance between the chondro-osseous junction within the growth plate and the proximal endpoint of the tetracycline label, and dividing the distance into three. Fluorescent line was viewed with an epifluorescence microscope (BX50, Olympus, Tokyo, Japan) and the distance was blind read with Image J software (NIH, Bethesda, MD, USA) by three different researchers to avoid the possible distinction among individuals.

\subsection{Growth Plate Height}

Cresyl violet (CV, Sigma Aldrich) staining of the chondrocytes was used to measure growth plate height. The heights of the overall growth plate, resting, proliferative and hypertrophic zone were measured at three different locations by using Image J software. The proliferative zone (PZ) was measured from flat chondrocytes aligned with the long axis of the bone presumed to be proliferative. The hypertrophic zone (HZ) was measured from chondrocyte with swollen nuclei and cytoplasm, which is easily distinguished based on size. The resting zone (RZ) was measured by subtraction of the height of proliferative and hypertrophic zones from the overall height of growth plate.

\subsection{Chondrocyte Proliferation}

To label S-phase nuclei for studies of chondrocyte proliferation, rats were injected intraperitoneally with BrdU (50 mg/kg, Sigma Aldrich) on days 8, 9 and 10. Dehydrated sagittal sections were pretreated as described previously [6] and reacted with BrdU-specific mouse antibody diluted 1/100 overnight at $4{ }^{\circ} \mathrm{C}$ (Santa Cruz Biotechnology, Santa Cruz, CA, USA). Sections were washed and reacted with FITC mouse antibody diluted 1/200 for $4 \mathrm{~h}$ (Jackson Immunoresearch Laboratories, West Grove, PA, USA). The chondrocyte proliferation was measured by the number of BrdU-labeled cells per unit area $\left(\mathrm{mm}^{2}\right)$ in the proximal tibial growth plate. 


\subsection{Immunohistochemistry}

To detect IGF-1 and BMP-2 expression in the growth plate, dehydrated sagittal sections of tibia were pretreated as described previously [9] and reacted with rabbit IGF-1 antibody and goat BMP-2 primary antibody diluted 1/200 overnight (Santa Cruz). The sections were washed, reacted with biotinylated rabbit antibody diluted 1/200 (Jackson Immunoresearch Laboratories) and incubated with avidin-biotin complex reagent diluted 1/100 (Vectastain ABC Kit, Vector Laboratories, Burlingame, CA, USA) for $1 \mathrm{~h}$, respectively. Sections were developed with 0.05\% 3,3-diaminobenzidine (Sigma Aldrich) solution containing hydrogen peroxide.

\subsection{Serum IGF-1 and IGFBP-3}

Thirty-three-day-old female Sprague-Dawley rats were obtained from Samtako and acclimatized for 7 days prior to the oral administration. Blood was collected from the jugular vein at $12 \mathrm{~h}$ after single administration of $P$. umbrosa at doses of 100, 300, and $1000 \mathrm{mg} / \mathrm{kg}$. Serum IGF-1 and IGFBP-3 were measured by specific ELISA kits according to the manufacturer's protocols (Biovendor, Modrice, Czech Republic).

\subsection{Statistical Analysis}

Statistical analyses were performed using GraphPad Prism 6 software (GraphPad Software, La Jolla, CA, USA). One-way analysis of variance (ANOVA) with post-hoc Bonferroni test for multiple comparisons. statistical significance was accepted at $p<0.05$ when the Bonferroni test was applied. All values were presented as mean \pm SD.

Acknowledgments: This study was supported by a grant of the Korean Health Technology R \& D Project, Ministry of Health \& Welfare, Korea (HI14C0976).

Author Contributions: D.L., H.S.K. and H.J.L. performed the experiments. H.G. prepared the extracts. Y.S.K. and J.S. contributed drafting the manuscript. H.K. conceived and designed the study.

Conflicts of Interest: The authors declare no conflict of interest.

\section{References}

1. Cohen, P.; Rogol, A.D.; Deal, C.L.; Saenger, P.; Reiter, E.O.; Ross, J.L.; Chernausek, S.D.; Savage, M.O.; Wit, J.M. Consensus statement on the diagnosis and treatment of children with idiopathic short stature: A summary of the growth hormone research society, the lawson wilkins pediatric endocrine society, and the european society for paediatric endocrinology workshop. J. Clin. Endocrinol. Metab. 2008, 93, 4210-4217. [PubMed]

2. Downie, A.B.; Mulligan, J.; Stratford, R.J.; Betts, P.R.; Voss, L.D. Are short normal children at a disadvantage? The wessex growth study. BMJ 1997, 314, 97-100. [CrossRef] [PubMed]

3. Stabler, B.; Clopper, R.R.; Siegel, P.T.; Stoppani, C.; Compton, P.G.; Underwood, L.E. Academic achievement and psychological adjustment in short children. The national cooperative growth study. J. Dev. Behav. Pediatr. 1994, 15, 1-6. [CrossRef] [PubMed]

4. Voss, L.D.; Sandberg, D.E. The psychological burden of short stature: Evidence against. Eur. J. Endocrinol. 2004, 151 (Suppl. S1), S29-S33. [CrossRef] [PubMed]

5. Zimet, G.D.; Owens, R.; Dahms, W.; Cutler, M.; Litvene, M.; Cuttler, L. Psychosocial outcome of children evaluated for short stature. JAMA Pediatr. 1997, 151, 1017-1023. [CrossRef]

6. Christensen, T.L.; Djurhuus, C.B.; Clayton, P.; Christiansen, J.S. An evaluation of the relationship between adult height and health-related quality of life in the general UK population. Clin. Endocrinol. 2007, 67, 407-412. [CrossRef] [PubMed]

7. Paajanen, T.A.; Oksala, N.K.; Kuukasjarvi, P.; Karhunen, P.J. Short stature is associated with coronary heart disease: A systematic review of the literature and a meta-analysis. Eur. Heart J. 2010, 31, 1802-1809. [CrossRef] [PubMed]

8. Wannamethee, S.G.; Shaper, A.G.; Whincup, P.H.; Walker, M. Adult height, stroke, and coronary heart disease. Am. J. Epidemiol. 1998, 148, 1069-1076. [CrossRef] [PubMed] 
9. Hindmarsh, P.C.; Dattani, M.T. Use of growth hormone in children. Nat. Clin. Pract. Endoc. 2006, 2, $260-268$. [CrossRef] [PubMed]

10. Wit, J.M.; Kamp, G.A.; Rikken, B. Spontaneous growth and response to growth hormone treatment in children with growth hormone deficiency and idiopathic short stature. Pediatr. Res. 1996, 39, $295-302$. [CrossRef] [PubMed]

11. Hintz, R.L.; Attie, K.M.; Baptista, J.; Roche, A. Effect of growth hormone treatment on adult height of children with idiopathic short stature. Genentech collaborative group. N. Engl. J. Med. 1999, 340, 502-507. [CrossRef] [PubMed]

12. Leschek, E.W.; Rose, S.R.; Yanovski, J.A.; Troendle, J.F.; Quigley, C.A.; Chipman, J.J.; Crowe, B.J.; Ross, J.L.; Cassorla, F.G.; Blum, W.F.; et al. Effect of growth hormone treatment on adult height in peripubertal children with idiopathic short stature: A randomized, double-blind, placebo-controlled trial. J. Clin. Endocrinol. Metab. 2004, 89, 3140-3148. [CrossRef] [PubMed]

13. August, G.P.; Julius, J.R.; Blethen, S.L. Adult height in children with growth hormone deficiency who are treated with biosynthetic growth hormone: The national cooperative growth study experience. Pediatrics 1998, 102, 512-516. [PubMed]

14. Bajpai, A.; Menon, P.S. Growth hormone therapy. Indian J. Pediatr. 2005, 72, 139-144. [CrossRef] [PubMed]

15. Bryant, J.; Baxter, L.; Cave, C.B.; Milne, R. Recombinant growth hormone for idiopathic short stature in children and adolescents. Cochrane DB Syst. Rev. 2007. [CrossRef]

16. Finkelstein, B.S.; Imperiale, T.F.; Speroff, T.; Marrero, U.; Radcliffe, D.J.; Cuttler, L. Effect of growth hormone therapy on height in children with idiopathic short stature: A meta-analysis. JAMA Pediatr. 2002, 156, 230-240. [CrossRef]

17. Hintz, R.L. Growth hormone: Uses and abuses. BMJ 2004, 328, 907-908. [CrossRef] [PubMed]

18. Silverman, B.L.; Blethen, S.L.; Reiter, E.O.; Attie, K.M.; Neuwirth, R.B.; Ford, K.M. A long-acting human growth hormone (nutropin depot): Efficacy and safety following two years of treatment in children with growth hormone deficiency. J. Pediatr. Endocr. Metab. 2002, 15 (Suppl. S2), 715-722. [CrossRef]

19. Hero, M.; Wickman, S.; Dunkel, L. Treatment with the aromatase inhibitor letrozole during adolescence increases near-final height in boys with constitutional delay of puberty. Clin. Endocrinol. 2006, 64, 510-513. [CrossRef] [PubMed]

20. Alba-Roth, J.; Muller, O.A.; Schopohl, J.; von Werder, K. Arginine stimulates growth hormone secretion by suppressing endogenous somatostatin secretion. J. Clin. Endocrinol. Metab. 1988, 67, 1186-1189. [CrossRef] [PubMed]

21. Stammers, A.L.; Lowe, N.M.; Medina, M.W.; Patel, S.; Dykes, F.; Perez-Rodrigo, C.; Serra-Majam, L.; Nissensohn, M.; Moran, V.H. The relationship between zinc intake and growth in children aged 1-8 years: A systematic review and meta-analysis. Eur. J. Clin. Nutr. 2015, 69, 147-153. [CrossRef] [PubMed]

22. Hamza, R.T.; Hamed, A.I.; Sallam, M.T. Effect of zinc supplementation on growth hormone-insulin growth factor axis in short egyptian children with zinc deficiency. Ital. J. Pediatr. 2012, 38, 21. [CrossRef] [PubMed]

23. Leem, K.; Park, S.Y.; Lee, D.H.; Kim, H. Lovastatin increases longitudinal bone growth and bone morphogenetic protein-2 levels in the growth plate of sprague-dawley rats. Eur. J. Pediatr. 2002, 161, 406-407. [CrossRef] [PubMed]

24. Wilsman, N.J.; Farnum, C.E.; Leiferman, E.M.; Fry, M.; Barreto, C. Differential growth by growth plates as a function of multiple parameters of chondrocytic kinetics. J. Orthop. Res. 1996, 14, 927-936. [CrossRef] [PubMed]

25. Shapiro, F. Bone development and its relation to fracture repair. The role of mesenchymal osteoblasts and surface osteoblasts. Eur. Cells Mater. 2008, 15, 53-76.

26. Shin, T.Y.; Lee, J.K. Effect of phlomis umbrosa root on mast cell-dependent immediate-type allergic reactions by anal therapy. Immunopharmacol Immunotoxicol. 2003, 25, 73-85. [CrossRef] [PubMed]

27. Shang, X.; Wang, J.; Li, M.; Miao, X.; Pan, H.; Yang, Y.; Wang, Y. Antinociceptive and anti-inflammatory activities of phlomis umbrosa turcz extract. Fitoterapia 2011, 82, 716-721. [CrossRef] [PubMed]

28. Shin, T.Y.; Kim, S.H.; Kim, D.K.; Leem, K.H.; Park, J.S. Phlomis umbrosa root inhibits mast cell-dependent allergic reactions and inflammatory cytokine secretion. Phytother. Res. 2008, 22, 153-158. [CrossRef] [PubMed] 
29. Limem-Ben Amor, I.; Boubaker, J.; Ben Sgaier, M.; Skandrani, I.; Bhouri, W.; Neffati, A.; Kilani, S.; Bouhlel, I.; Ghedira, K.; Chekir-Ghedira, L. Phytochemistry and biological activities of phlomis species. J. Ethnopharmacol. 2009, 125, 183-202. [CrossRef] [PubMed]

30. Li, M.X.; Shang, X.F.; Jia, Z.P.; Zhang, R.X. Phytochemical and biological studies of plants from the genus phlomis. Chem. Biodivers. 2010, 7, 283-301. [CrossRef] [PubMed]

31. Jiang, W.; Zhang, S.; Fu, F.; Zhu, H.; Hou, J. Inhibition of nuclear factor-kappab by 6-O-acetyl shanzhiside methyl ester protects brain against injury in a rat model of ischemia and reperfusion. J. Neuroinflamm. 2010, 7. [CrossRef] [PubMed]

32. Kang, Z.C.; Jiang, W.L.; Xu, Y.; Zhu, H.B.; Hou, J. Cardioprotection with 8-O-acetyl shanzhiside methylester on experimental myocardial ischemia injury. Eur. J. Pharm Sci. 2012, 47, 124-130. [CrossRef] [PubMed]

33. Zhang, L.; Kan, Z.C.; Zhang, X.L.; Fang, H.; Jiang, W.L. 8-O-acetyl shanzhiside methylester attenuates cerebral ischaemia/reperfusion injury through an anti-inflammatory mechanism in diabetic rats. Basic Clin. Pharmacol. 2014, 115, 481-487. [CrossRef] [PubMed]

34. Sims, N.A.; Clement-Lacroix, P.; da Ponte, F.; Bouali, Y.; Binart, N.; Moriggl, R.; Goffin, V.; Coschigano, K.; Gaillard-Kelly, M.; Kopchick, J.; et al. Bone homeostasis in growth hormone receptor-null mice is restored by igf-i but independent of stat5. J. Clin. Investig. 2000, 106, 1095-1103. [CrossRef] [PubMed]

35. Yakar, S.; Rosen, C.J. From mouse to man: Redefining the role of insulin-like growth factor-I in the acquisition of bone mass. Exp. Biol. Med. 2003, 228, 245-252.

36. Van der Eerden, B.C.; Karperien, M.; Wit, J.M. Systemic and local regulation of the growth plate. Endocr. Rev. 2003, 24, 782-801. [CrossRef] [PubMed]

37. Hansson, L.I.; Stenstrom, A.; Thorngren, K.G. Skeletal deposition and toxicity of methacycline. Nature 1968, 219, 624-625. [CrossRef] [PubMed]

38. Beauloye, V.; Muaku, S.M.; Lause, P.; Portetelle, D.; Renaville, R.; Robert, A.R.; Ketelslegers, J.M.; Maiter, D. Monoclonal antibodies to growth hormone (GH) prolong liver GH binding and GH-induced IGF-I/Igfbp-3 synthesis. Am. J. Physiol. 1999, 277, E308-E315. [PubMed]

39. Han, S.H. Effect of the Active Compounds in Phlomidis Radix on Bone Regeneration in Primary Cultured Osteoblasts Derived from Alveolar Bone. Ph.D. Thesis, Wonkwang University, Jeollabuk-do, Korea, 2004.

40. Kim, S.Y. Effect of Physiologically Active Compounds in Phlomidis Radix on Bone Regeneration. Ph.D. Thesis, Wonkwang University, Jeollabuk-do, Korea, 2004.

41. Kim, J.Y.; Lee, J.I.; Song, M.; Lee, D.; Song, J.; Kim, S.Y.; Park, J.; Choi, H.Y.; Kim, H. Effects of eucommia ulmoides extract on longitudinal bone growth rate in adolescent female rats. Phytother. Res. 2015, 29, 148-153. [CrossRef] [PubMed]

42. Hunziker, E.B. Mechanism of longitudinal bone growth and its regulation by growth plate chondrocytes. Microsc. Res. Tech. 1994, 28, 505-519. [CrossRef] [PubMed]

43. Farnum, C.E.; Lee, R.; O'Hara, K.; Urban, J.P. Volume increase in growth plate chondrocytes during hypertrophy: The contribution of organic osmolytes. Bone 2002, 30, 574-581. [CrossRef]

44. Breur, G.J.; VanEnkevort, B.A.; Farnum, C.E.; Wilsman, N.J. Linear relationship between the volume of hypertrophic chondrocytes and the rate of longitudinal bone growth in growth plates. J. Orthop. Res. 1991, 9, 348-359. [CrossRef] [PubMed]

45. Hansson, L.I. Daily growth in length of diaphysis measured by oxytetracycline in rabbit normally and after medullary plugging. Acta Orthop. Scand. 1967. [CrossRef]

46. Kuhn, J.L.; DeLacey, J.H.; Leenellett, E.E. Relationship between bone growth rate and hypertrophic chondrocyte volume in new zealand white rabbits of varying ages. J. Orthop. Res. 1996, 14, 706-711. [CrossRef] [PubMed]

47. Gratzner, H.G. Monoclonal antibody to 5-bromo- and 5-iododeoxyuridine: A new reagent for detection of DNA replication. Science 1982, 218, 474-475. [CrossRef] [PubMed]

48. Yakar, S.; Liu, J.L.; Stannard, B.; Butler, A.; Accili, D.; Sauer, B.; LeRoith, D. Normal growth and development in the absence of hepatic insulin-like growth factor I. Proc. Natl. Acad. Sci. USA 1999, 96, 7324-7329. [CrossRef] [PubMed]

49. Sjogren, K.; Liu, J.L.; Blad, K.; Skrtic, S.; Vidal, O.; Wallenius, V.; LeRoith, D.; Tornell, J.; Isaksson, O.G.; Jansson, J.O.; et al. Liver-derived insulin-like growth factor I (IGF-I) is the principal source of IGF-I in blood but is not required for postnatal body growth in mice. Proc. Natl. Acad. Sci. USA 1999, 96, 7088-7092. [CrossRef] [PubMed] 
50. De Luca, F.; Barnes, K.M.; Uyeda, J.A.; de-Levi, S.; Abad, V.; Palese, T.; Mericq, V.; Baron, J. Regulation of growth plate chondrogenesis by bone morphogenetic protein-2. Endocrinology 2001, 142, 430-436. [CrossRef] [PubMed]

51. Wu, S.; Yang, W.; de Luca, F. Insulin-like growth factor-independent effects of growth hormone on growth plate chondrogenesis and longitudinal bone growth. Endocrinology 2015, 156, 2541-2551. [CrossRef] [PubMed]

52. Barrios, V.; Argente, J.; Munoz, M.T.; Pozo, J.; Chowen, J.A.; Hernandez, M. Diagnostic interest of acid-labile subunit measurement in relationship to other components of the igf system in pediatric patients with growth or eating disorders. Eur. J. Endocrinol. 2001, 144, 245-250. [CrossRef] [PubMed]

53. Rosenfeld, R.G. Is growth hormone deficiency a viable diagnosis? J. Clin. Endocrinol. MeTab. 1997, 82, 349-351. [CrossRef] [PubMed]

54. Van der Kaay, D.C.; Hendriks, A.E.; Ester, W.A.; Leunissen, R.W.; Willemsen, R.H.; de Kort, S.W.; Paquette, J.R.; Hokken-Koelega, A.C.; Deal, C.L. Genetic and epigenetic variability in the gene for IGFBP-3 (IGFBP3): Correlation with serum IGFBP-3 levels and growth in short children born small for gestational age. Growth Horm. IGF Res. 2009, 19, 198-205. [CrossRef] [PubMed]

55. Costalonga, E.F.; Antonini, S.R.; Guerra-Junior, G.; Mendonca, B.B.; Arnhold, I.J.; Jorge, A.A. The -202 a allele of insulin-like growth factor binding protein-3 (IGFBP3) promoter polymorphism is associated with higher IGFBP-3 serum levels and better growth response to growth hormone treatment in patients with severe growth hormone deficiency. J. Clin. Endocrinol. Metab. 2009, 94, 588-595. [CrossRef] [PubMed]

56. Firth, S.M.; Baxter, R.C. Cellular actions of the insulin-like growth factor binding proteins. Endocr. Rev. 2002, 23, 824-854. [CrossRef] [PubMed]

Sample Availability: Sample of the P. umbrosa extract is available from the authors.

(C) 2016 by the authors; licensee MDPI, Basel, Switzerland. This article is an open access article distributed under the terms and conditions of the Creative Commons by Attribution (CC-BY) license (http://creativecommons.org/licenses/by/4.0/). 